\title{
Effect of intensive exercise on patients with active rheumatoid arthritis: a randomised clinical trial
}

\author{
C H M van den Ende, F C Breedveld, S le Cessie, B A C Dijkmans, A W de Mug, \\ J M W Hazes
}

Department of Rheumatology, Leiden University Medical Centre, Leiden, The Netherlands C H M van den Ende F C Breedveld $\mathrm{J} M$ W Hazes

Department of Medical Statistics, Leiden University Medical Centre $\mathrm{S}$ le Cessie

Department of Rheumatology, Free University Hospital Amsterdam, Amsterdam, The

Netherlands B A C Dijkmans

Department of Physical Therapy, Leiden University Medical Centre A W de Mug

Correspondence to: Dr C H M van den Ende, Leiden University Medica Centre, Department of Rheumatology, C4-R, Postbox 9600, 2300 RC Leiden, The Netherlands Email:

e.vandenende@nivel.n

Accepted for publication 9 February 2000

\begin{abstract}
Objective-To investigate the effects of a dynamic, intensive exercise regimen on pain, disease activity, and physical functioning in active rheumatoid arthritis (RA).

Methods-64 patients with RA with a mean age of 60 (13) years and mean disease duration of 8 (8) years, admitted to hospital because of active disease, were randomly assigned to an intensive exercise programme or to a conservative exercise programme during their period in hospital with a mean length of 30 (14) days. The intensive exercise programme consisted of knee and shoulder dynamic and isometric muscle strengthening exercises against resistance five times a week and conditioning bicycle training three times a week and was supplemental to the conservative exercise programme of range of motion and isometric exercises. Indices of disease activity, pain, muscle strength, and functional ability were assessed at $0,3,6,12$, and 24 weeks by a blinded observer.
\end{abstract}

Results-The medical treatment during the study was the same in both groups. Both groups improved in measures of disease activity, differences between groups were not statistically significant. The mean improvement in disease activity score at 24 weeks in the intensive and conservative exercise group was $-1.4(1.5)$ and -0.7 (1.4), respectively. Measures of physical functioning improved significantly for patients in the intensive exercise group, and differences between groups were statistically significant for measures of muscle strength.

Conclusion-A short term intensive exercise programme in active RA is more effective in improving muscle strength than a conservative exercise programme and does not have deleterious effects on disease activity.

(Ann Rheum Dis 2000;59:615-621)

Owing to a fear of enhancing joint inflammation and accelerating cartilage destruction it has been advocated that exercise treatment in active rheumatoid arthritis (RA) should be restricted to gentle assisted range of motion (ROM) exercises. ${ }^{1-3}$ In subacute phases isometric exercises which put little stress on the joints are recommended. So far, research on the conservative management of active RA has focused on the best amount of immobilisation and bed rest, ${ }^{4-6}$ which are considered important components of the management of active RA. However, the risks of bed rest and immobilisation are well known. Loss of muscle strength during immobilisation may add up to $1-2 \%$ a day, ${ }^{7-11}$ and is more pronounced in the presence of joint disease or injury. ${ }^{12-14} \mathrm{~A}$ decline of cardiorespiratory function even occurs in healthy subjects during voluntary bed rest with a moderate exercise regimen. ${ }^{15}$ In healthy subjects the time to recover exceeds the time of immobilisation. ${ }^{7}$

Active disease may persist for a prolonged period of time and a conservative exercise regimen may be inadequate to prevent a decline in physical functioning. Dynamic exercises have been shown to be more effective in improving muscle strength and cardiorespiratory function than a conservative exercise regimen in patients with stable RA. ${ }^{16-18}$ An intensive exercise regimen including dynamic exercises against resistance might also be of value in active RA, provided that these exercises do not increase symptoms. The primary aim of this study was to examine the consequences of an intensive exercise regimen on disease activity in active RA. In addition, the efficacy of an intensive exercise programme in active RA on physical functioning was studied.

\section{Patients and methods}

Sixty four consecutive patients admitted to hospital for multidisciplinary treatment in a rheumatology clinic because of active RA and loss of functional ability participated in the study. All patients fulfilled the following inclusion criteria: (1) RA according to the 1987 American Rheumatism Association criteria ${ }^{19}$; (2) active disease as determined by the presence of six or more swollen joints and at least two of the following criteria: (a) morning stiffness of more than 45 minutes; $(b)$ tender joint count $>9$; and $(c)$ Westergren erythrocyte sedimentation rate (ESR) $>28 \mathrm{~mm} / 1 \mathrm{st} \mathrm{h}$; (3) age between 20 and 80 years; and (4) ability to walk 50 feet $(15 \mathrm{~m})$ indoors. Exclusion criteria were the presence of arthroplasties of the knee joints and inability to tolerate training owing to the presence of serious cardiac or lung disease. All patients received primary nursing care and had to keep to fixed hours for rest-about two hours a day. ROM and isometric muscle strengthening exercises supervised by exercise therapists were carried out daily. An occupational therapist informed the patients about joint protection and provided joints splints if considered necessary. A social worker focused on psychosocial problems related to the 
disease. The medical treatment consisted of optimisation of the use of non-steroidal antiinflammatory drugs (NSAIDs), the institution of disease modifying antirheumatic drugs (DMARDs), and intra-articular injections with corticosteroids, if necessary.

STUDY DESIGN

The study design was a single blinded, randomised trial of the effect of an intensive exercise programme additional to the conservative exercise regimen during the period of stay in hospital. The study was approved by the medical ethical committee of the hospital. After informed consent patients were included in the trial within the first three days after admission to hospital. Patients were stratified by sex and randomly allocated by an independent person to the intensive or the conservative exercise programme by means of sealed, opaque envelopes. Allocation took place immediately after the baseline assessments.

\section{EXERCISE PROGRAMMES}

All patients participating in the study followed the usual conservative exercise programme of ROM exercises and isometric exercises. All joint movements of the hands and feet were exercised throughout the entire possible range of motion and repeated twice. The movements were active-assisted, performed at a low pace. In addition, isometric exercises of the larger joints were performed without resistance. Exercises were carried out in prone and sitting positions. The exercises were individually supervised by exercise therapists four times a week. Once a week all patients underwent a group session of active ROM exercises sitting on a chair. In addition to the supervised exercise sessions, patients were encouraged to exercise on their own.

Patients allocated to the intensive exercise regimen received, individually, extra exercises supplemental to the conservative exercise programme. The intensive exercise programme was supervised by exercise therapists not involved in the conservative exercise programme. The isometric and isokinetic strength of the knee extensors and flexors was reciprocally trained on an isokinetic dynamometer (EnKnee, Enraf Nonius, Delft, The Netherlands). The isometric training comprised three series of five contractions at $70 \%$ maximum voluntary contraction (MVC) during six seconds with the knee joint in $45^{\circ}$ flexion. Between each series the time to recover was at least 30 seconds. The isokinetic strength of both knees was trained by three series of eight reciprocal contractions at $70 \% \mathrm{MVC}$ at an angular velocity of $60 \%$ s. To control the exercise load MVC was determined every week by the exercise therapist. Because of the stabilising function of the shoulder, girdle muscles around the shoulder were isometrically trained in a prone position by performing six contractions of six seconds in alternate directions against manual resistance such that the patients were just able to hold the starting position.

In addition to the muscle strengthening exercises, patients bicycled three times a week during 15 minutes on a home trainer. During cycling heart rate was maintained at $60 \%$ of the age predicted maximum.

A strict policy about adjusting the exercise load in cases of excessive pain and fatigue during and after exercising was followed. Adjustments to the intensive exercise programme were accurately recorded each exercise session.

\section{ASSESSMENTS}

All assessments were carried out by a single observer who was blinded for the allocation of the exercise programmes. Patients were evaluated at the start of their stay in hospital, then at $3,6,12$, and 24 weeks after admission.

\section{DISEASE ACTIVITY}

Disease activity was assessed by the following variables: number of swollen joints, number of tender joints (range 0-28), ${ }^{20} \mathrm{ESR}$, and the patient's score on visual analogue scale (VAS) for pain and disease activity. Furthermore, the disease activity score (DAS) ${ }^{21}$ was determined. The study did not interfere with the routine drug treatment. Any changes in drugs were recorded at each assessment. The number of responders was determined by using a modified set of the American College of Rheumatology (ACR) criteria for improvement in RA. ${ }^{22}$ For practical reasons it was not possible to rate the doctor's global assessment at each evaluation. Therefore, we arbitrarily substituted grip strength for the doctor's global assessment. Consequently, improvement was defined as $\geqslant 20 \%$ improvement in tender or swollen joints counts and $\geqslant 20 \%$ improvement in at least three of the following five measures: ESR, pain and patient's global assessment scored on a VAS, grip strength, and Health Assessment Questionnaire (HAQ).

\section{MUSCLE STRENGTH}

Knee extensor and flexor strength was measured with an isokinetic dynamometer (Enknee, Enraf Nonius, Delft, The Netherlands) by a standardised test procedure. The peak torque of four attempts of isokinetic strength and $60 \%$ angle velocity and the peak torque of three attempts of isometric contractions were used as indicators of muscle strength.

\section{JOINT MOBILITY}

ROM was assessed with the Escola Paulista de Medicina (EPM)-ROM scale, ${ }^{23}{ }^{24}$ a measure for joint mobility derived from 10 selected joint motions of a number of smaller and larger joints.

\section{FUNCTIONAL ABILITY}

At each assessment patients completed the $\mathrm{HAQ}^{25}$ validated for Dutch patients ${ }^{26}$ with RA. Functional performance was observed by a walk test (time needed to walk a distance of 50 feet) and the grip strength determined by a Martin vigorimeter.

\section{STATISTICAL ANALYSIS}

The primary aim of the study was to examine the effect of intensive exercise on disease activity. Therefore, the number of swollen joints was 
Table 1 Demographic and clinical data of 64 patients participating in the study. Figures are presented as means (SD) unless otherwise stated

\begin{tabular}{|c|c|c|c|c|c|c|}
\hline & \multicolumn{3}{|c|}{$\begin{array}{l}\text { Intensive exercise group } \\
(n=34)\end{array}$} & \multicolumn{3}{|c|}{$\begin{array}{l}\text { Conservative exercise } \\
\text { group }(n=30)\end{array}$} \\
\hline Women/men & \multicolumn{3}{|c|}{$20 / 14$} & \multicolumn{3}{|c|}{$20 / 10$} \\
\hline Age (years) & \multicolumn{3}{|c|}{$62(13)$} & \multicolumn{3}{|c|}{$58(14)$} \\
\hline Disease duration (years) & \multicolumn{3}{|c|}{$8(8)$} & \multicolumn{3}{|c|}{$7(8)$} \\
\hline \multicolumn{7}{|l|}{ No of patients (\%) } \\
\hline With positive $\mathrm{RF}^{\star}$ & \multicolumn{3}{|c|}{$30(88)$} & \multicolumn{3}{|c|}{$19(63)$} \\
\hline With erosions & \multicolumn{3}{|c|}{$26(79) \dagger$} & \multicolumn{3}{|c|}{$24(80)$} \\
\hline $\mathrm{ESR}^{\star}(\mathrm{mm} / 1 \mathrm{st} \mathrm{h})$ & \multicolumn{3}{|c|}{$67(30)$} & \multicolumn{3}{|c|}{$58(37)$} \\
\hline Swollen joint count $(\max =28)$ & \multicolumn{3}{|c|}{$16(5)$} & \multicolumn{3}{|c|}{$16(5)$} \\
\hline $\mathrm{HAQ}^{\star}$ & \multicolumn{3}{|c|}{$1.8(0.8)$} & \multicolumn{3}{|c|}{$1.7(0.6)$} \\
\hline No of prescribed second-line drugs & \multicolumn{3}{|c|}{$2.2(1.9)$} & \multicolumn{3}{|c|}{$2.4(1.9)$} \\
\hline No of patients treated at (w) with: & $0 w$ & $6 w$ & $24 w$ & $0 w$ & $6 w$ & $24 w$ \\
\hline No drugs & 13 & 2 & 1 & 8 & 1 & 0 \\
\hline Sulfasalazine & 9 & 13 & 12 & 8 & 7 & 3 \\
\hline Methotrexate & 4 & 5 & 5 & 7 & 11 & 10 \\
\hline Prednisolone & 3 & 6 & 4 & 3 & 3 & 3 \\
\hline Other second line drugs & 7 & 10 & 12 & 5 & 8 & 9 \\
\hline
\end{tabular}

${ }^{\star} \mathrm{RF}=$ rheumatoid factor; ESR $=$ Westergren erythrocyte sedimentation rate; HAQ $=$ Health Assessment Questionnaire.

†Data for one patient are missing.

chosen as the primary outcome measure. A difference in improvement in the number of swollen joints of $20 \%$ during the first 3 weeks between the intensive exercise group and the conservative exercise group was considered clinically relevant. A sample size of 28 patients for each exercise regimen was required to detect a $20 \%$ difference in improvement of swollen joints between the intensive and conservative exercise regimen with a significance level of 0.05 and a power of $90 \%$, assuming the mean number of swollen joints to be 15 at baseline and the standard deviation of the changes scores to be 3.5. Sample sizes were

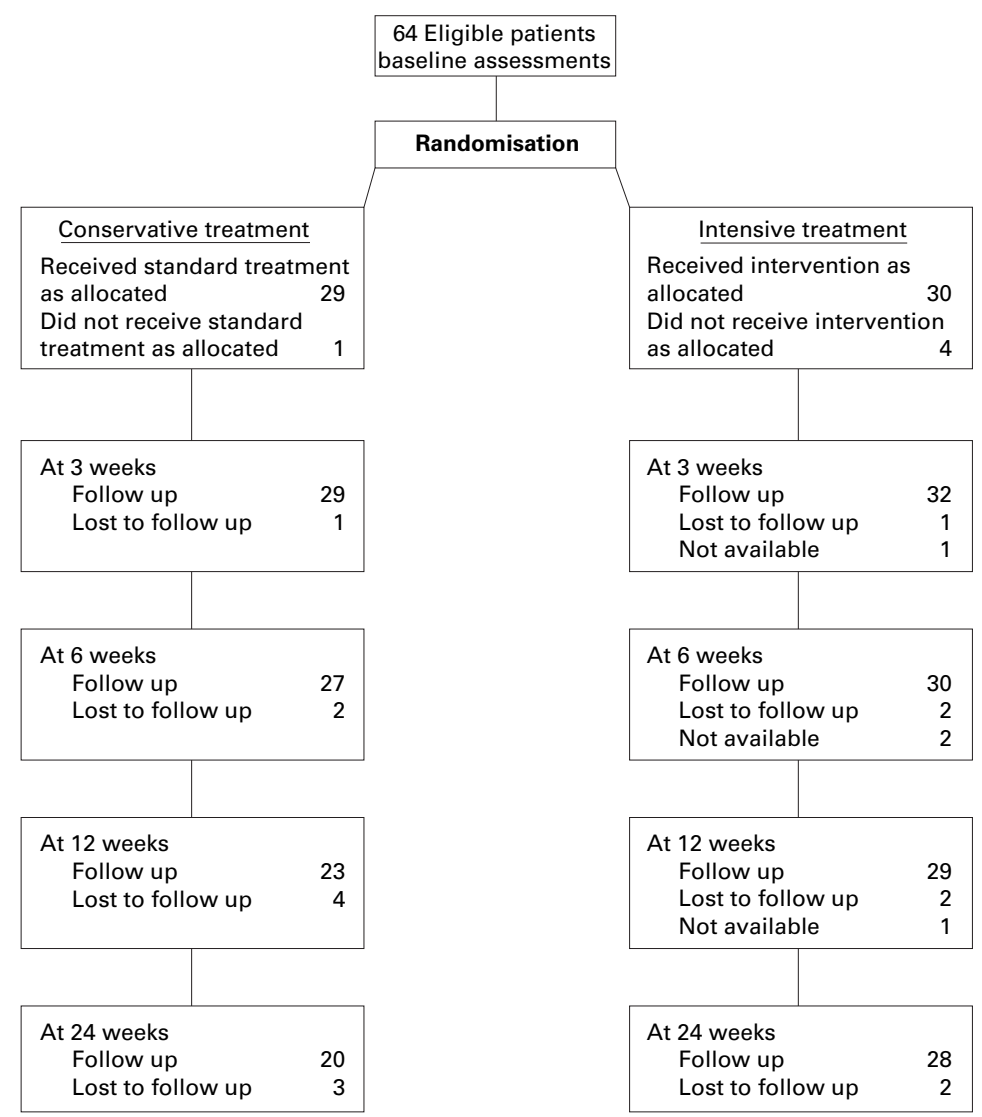

Figure 1 Flow chart of the number of patients who completed the study according to the protocol and the number of patients who did not complete the allocated treatment or were lost to follow up. set at 32 patients per group, allowing for possible dropouts. After completing the study it was calculated that a sample size of 32 is also large enough to detect a $7 \%$ (0.5 unit DAS score) difference between the two groups in improvement of the DAS score with a significance level of 0.05 and a power of $90 \%$ assuming the mean number of DAS score to be 7.0 at baseline and the standard deviation of the changes scores to be 0.7 (figures derived from data on DAS scores at baseline and three weeks).

At each assessment in several patients the muscle strength of the knee could not be assessed because of pain. Because of the inability to test the muscle strength owing to pain, which was assumed to be related to treatment outcomes, all values of muscle strength were transformed. Missing values because of pain were replaced with zero, values from 1 to 10 were replaced with 1 , from 11 to 20 with 2 , and so on. Values beyond 120 were replaced with 13 , resulting in new variables ranging from 0 to 13. The transformed variables were handled as continuous variables.

All outcome measures were analysed on an intention to treat basis. Changes in measures of disease activity and measures of joint mobility, muscle strength, and functional ability were examined by calculating $95 \%$ confidence intervals of the difference between baseline and evaluation scores. Between-group differences in change scores were investigated by Student's $t$ test for unpaired samples.

Differences in clinical and demographic variables at baseline between the patients who were lost to follow up during the observation period of 24 weeks and patients who completed the study were examined by $\chi^{2}$ test or by Student's $t$ test, where appropriate.

\section{Results}

Table 1 presents the demographic and clinical characteristics of the participating patients. The patients with a mean age of 60 (13) years and mean disease duration of 8 (8) years, had high disease activity and their daily functioning was severely restricted. Thirty four patients were allocated to the intensive exercise programme, 30 patients to the conservative exercise programme. There were no significant differences between the groups in any of the assessed demographic and clinical measures except for pain scored on a VAS. The pain on a VAS was lower in the patients in the intensive exercise group than in the conservative exercise group, 4.6 and 5.9 respectively $(\mathrm{p}=0.03)$. The mean length of stay in hospital in the intensive and conservative exercise groups was 31 (16) days and 28 (13) respectively. Eleven patients in the intensive exercise group and eight in the conservative exercise group were still in hospital at the evaluation at six weeks.

\section{LOST TO FOLLOW UP}

The number of patients lost to follow up during the observation period is illustrated by a flow chart (fig 1). One patient in the conservative exercise programme was within two days after allocation transferred to a general hospital because of fever with unknown cause and lost 
Table 2 Mean changes (95\% CI) and mean differences (95\% CI) in change scores between groups in variables of pain and disease activity in 64 patients randomly assigned to an intensive or conservative exercise programme during a stay in hospital

\begin{tabular}{|c|c|c|c|c|c|}
\hline & \multicolumn{2}{|c|}{ Intensive exercise } & \multicolumn{2}{|c|}{ Conservative exercise } & \multirow[b]{2}{*}{ Mean difference $(95 \% \mathrm{CI})$} \\
\hline & $n$ & $\Delta^{\star} 95 \% C I^{\star}$ & $n$ & $\triangle 95 \% C I$ & \\
\hline \multicolumn{6}{|l|}{ Swollen joints } \\
\hline Baseline $\left(\mathrm{SD}^{\star}\right)$ & 34 & $16(5)$ & 30 & $16(5)$ & \\
\hline$\Delta$ week 3 & 32 & $1(-1$ to 3$)$ & 29 & $0(-2$ to 2$)$ & $1(-3$ to 1$)$ \\
\hline$\Delta$ week 6 & 29 & $-1(-3$ to 1$)$ & 27 & $-1(-3$ to 0$)$ & $0(-2$ to 3$)$ \\
\hline$\Delta$ week 12 & 28 & $-2(-5$ to 0$)$ & 23 & $-1(-3$ to 2$)$ & $-2(-5$ to 2$)$ \\
\hline$\Delta$ week 24 & 28 & $-6(-9$ to -3$)$ & 20 & $-3(-6$ to 0$)$ & $-2(-7$ to 2$)$ \\
\hline \multicolumn{6}{|l|}{$E S R^{\star}$} \\
\hline Baseline (SD) & 34 & $67(30)$ & 30 & $58(37)$ & \\
\hline$\Delta$ week 3 & 32 & $3(-3$ to 8$)$ & 28 & $1(-5$ to 7$)$ & $2(-6$ to 10$)$ \\
\hline$\Delta$ week 6 & 27 & $1(-8$ to 10$)$ & 25 & $2(-4$ to 8$)$ & $-1(-9$ to 11$)$ \\
\hline$\Delta$ week 12 & 27 & $-9(-20$ to 1$)$ & 22 & $-2(-9$ to 5$)$ & $-8(-21$ to 6$)$ \\
\hline$\Delta$ week 24 & 26 & $-22(-34$ to -10$)$ & 17 & $-4(-17$ to 9$)$ & $-18(-35$ to 0$)$ \\
\hline \multicolumn{6}{|c|}{ Pain on VAS $(\mathrm{cm})^{\star}$} \\
\hline Baseline (SD) & 34 & $4.4(2.0)$ & 29 & $5.9(2.5)$ & \\
\hline$\Delta$ week 3 & 32 & $-0.4(-1.2$ to 0.4$)$ & 28 & $-1.6(-2.3$ to -0.9$)$ & $1.2(0.1$ to 2.3$) \dagger$ \\
\hline$\Delta$ week 6 & 29 & $-1.2(-2.1$ to -0.2$)$ & 26 & $-1.2(-2.0$ to -0.5$)$ & $0.1(-1.1$ to 1.2$)$ \\
\hline$\Delta$ week 12 & 30 & $-1.5(-2.2$ to -0.7$)$ & 24 & $-1.9(-3.1$ to -0.6$)$ & $0.4(-1.0$ to 1.8$)$ \\
\hline$\Delta$ week 24 & 27 & $-1.7(-2.6$ to -0.8$)$ & 21 & $-1.8(-3.0$ to -0.6$)$ & $0.1(-1.4$ to 1 to 5$)$ \\
\hline \multicolumn{6}{|l|}{$D A S^{\star}$} \\
\hline Baseline (SD) & 34 & $7.0(0.9)$ & 30 & $7.0(0.8)$ & \\
\hline$\Delta$ week 3 & 30 & $-0.2(-0.4$ to 0.1$)$ & 26 & $-0.4(-0.7$ to -0.2$)$ & $0.3(-0.1$ to 0.6$)$ \\
\hline$\Delta$ week 6 & 25 & $-0.4(-0.9$ to 0.1$)$ & 24 & $-0.4(-0.6$ to -0.2$)$ & $-0.1(-0.6$ to 0.5$)$ \\
\hline$\Delta$ week 12 & 24 & $-0.9(-1.6$ to -0.3$)$ & 20 & $-0.4(-0.8$ to 0.0$)$ & $-0.6(-1.4$ to 0.2$)$ \\
\hline$\Delta$ week 24 & 24 & $-1.4(-2.0$ to -0.7$)$ & 17 & $-0.7(-1.4$ to 0.0$)$ & $-0.7(-1.6$ to 0.3$)$ \\
\hline
\end{tabular}

${ }^{\star} \Delta=$ mean change; $\mathrm{CI}=$ confidence interval; $\mathrm{SD}=$ standard deviation; VAS = visual analogue scale; ESR = erythrocyte sedimentation rate; DAS = disease activity score.

†Significant difference between groups.

to follow up. In four cases, all in the intensive exercise group, patients could not be evaluated at one time point for various reasons.

At 24 weeks a total of 16 patients ( 6 in the intensive and 10 in the conservative exercise group) with a mean age of 62 (12) years and a mean disease duration of 8 (9) years were lost to follow up. In the intensive exercise group the reasons for this loss to follow up were death not related to RA $(n=1)$, stay in hospital because of knee surgery planned before admission $(n=1)$, personal circumstances $(n=1)$, psychological strain $(n=1)$, and difficulty in transport to the rheumatology clinic $(n=2)$. In the conservative group the reasons were comorbidity related to RA $(n=4)$, depression $(n=1)$, difficulty in transport to the rheumatology clinic $(n=3)$, and non-compliance $(n=2)$. There were only slight, statistically insignificant differences in demographic and clinical variables at baseline between the patients who completed the trial and the patients who were lost to follow up (data not shown).

\section{COMPLIANCE WITH THE INTENSIVE EXERCISE} PROGRAMME

Four patients in the intensive exercise programme left the programme prematurely, two patients experienced too much psychological strain due to the extra exercise sessions and two patients dropped out in the course of their period in hospital because of an increase in pain. Three of those four patients were not lost to follow up and included in the analysis. The mean (SD) number of intensive exercise sessions was 16 (9). In $28 / 34(82 \%)$ of the patients in the intensive exercise programme the resistance or the exercise time was lowered during conditioning exercises on the home trainer because of too much pain or fatigue in, on average, $55 \%$ of the exercise sessions of these patients. Similarly, the exercise load of the resistance exercises was adjusted in 22/34 $(65 \%)$ of the patients in $50 \%$ of the exercise sessions, on average.

\section{MEASURES OF DISEASE ACTIVITY}

Table 1 shows the use of drugs in both groups. In about $50 \%$ of the patients a new second line drug was started in the first six weeks. The number of intra-articular injections was higher in the intensive exercise groups, but differences between groups were not significant.

Both patient groups showed a gradual decline in measures of disease activity during the observation period of 24 weeks (table 2). In general, the improvement in measures of disease activity was greater in the patients of the intensive exercise group. The patients in the intensive exercise programme showed a slight increase in the number of swollen joints at three weeks, followed by a decline thereafter (fig 2). There were no significant differences in the number of swollen joints at any evaluation. ESR, the numbers of tender and swollen joints were significantly decreased at 24 weeks in the dynamic group, but not in the conservative group. Pain scored on a VAS was at three weeks significantly more improved in the conservative group than in the intensive group (mean change scores $-1.6 \quad v \quad-0.4$ respectively, $\mathrm{p}=0.03)$. At later assessments the improvement in pain was the same in both groups. Fifteen patients in the intensive exercise programme and six patients in the conservative exercise programme met the modified response ACR criteria at one or more times during follow up. At 24 weeks the number of responders in the intensive exercise group was significantly 

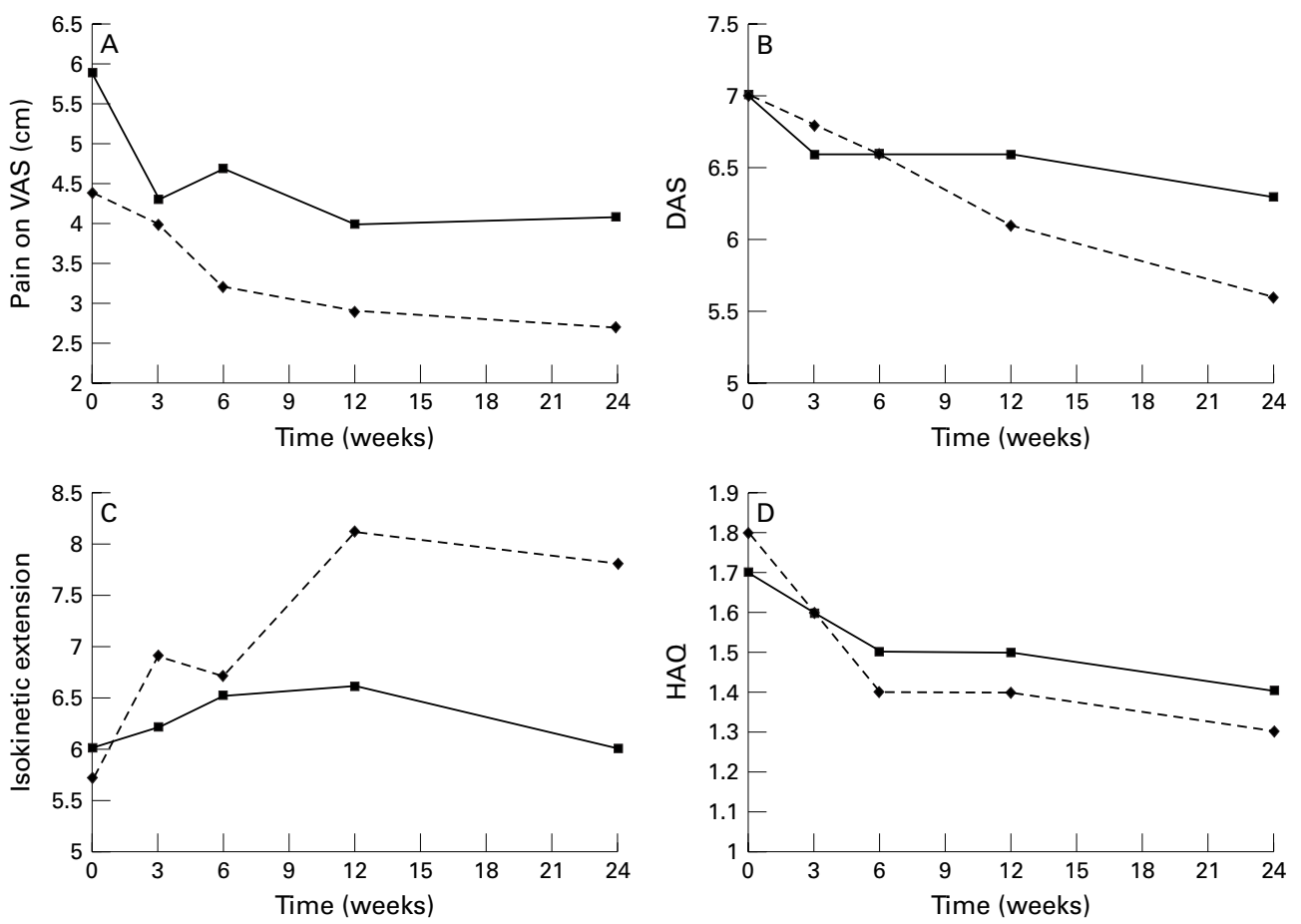

$\rightarrow-$ Conservative exercise

- Intensive exercise

Figure 2 Mean values of variables of $(A)$ pain measured by a visual analogue scale (VAS); (B) disease activity score (DAS); (C) muscle strength; and (D) functional ability at 0, 3, 6, 12, and 24 weeks in patients randomly assigned to the conservative exercise group and the intensive exercise group.

higher than in the conservative exercise group (12 $v 3$ respectively, $\mathrm{p}=0.04)$.

MEASURES OF JOINT MOBILITY, MUSCLE

STRENGTH, AND FUNCTIONAL ABILITY

During the observation period of 24 weeks measures of joint mobility, muscle strength, and functional ability improved in both groups (table 3). The patients in the intensive exercise programme were significantly improved in joint mobility at 12 and 24 weeks, but differences between groups were not statistically significant. Patients in the intensive exercise group showed a gradual, but marked increase in isometric and isokinetic muscle strength, resulting in an improvement of about $30 \%$ at 24 weeks, whereas the patients in the conservative group first showed a slight increase in muscle strength, followed by a decline thereafter (fig 2). The HAQ score in both patient groups improved over time, but the HAQ score in the intensive exercise programme improved about $0.2 \mathrm{HAQ}$ units more. Differences between groups in HAQ scores were not statistically significant.

\section{Discussion}

The results of our study suggest that a short term programme of intensive exercises is well tolerated by patients with active disease. Furthermore, patients in the intensive exercise programme showed a statistically significant improvement of muscle strength after completion of the exercise programme and after six months of follow up. Several studies have already shown the benefit of intensive exercise in well controlled RA. ${ }^{27}$ To our knowledge our study is the first on the effect of intensive exercise treatment in patients with active disease.

The results of our study might be biased by the relatively high number of patients who were lost to follow up. After discharge many patients had to travel a long distance to the rheumatology clinic to come to the follow up assessments and many were too disabled to travel on their own. Comorbidity was one of the major reasons for withdrawing from the study. Considering the absence of relevant differences between patients who were lost to follow up and patients who completed the study and given the distribution of the reasons for loss to follow up between the two groups, we conclude that the results of our study are not essentially influenced by missing data.

An unexpected finding was the difference in the rate of improvement of disease activity between the two groups in favour of the intensive exercise group. In particular, in the period after leaving hospital patients in the intensive exercise group improved more in all measures of disease activity. In our opinion the small differences in the use of second line drugs (table 1) between the groups do not sufficiently explain the differences in the rate of improvement in disease activity between the groups seen in our study. Possibly, the difference in improvement of disease activity between the groups occurred by chance. An effect of the intensive, dynamic exercises on disease activity cannot completely be excluded, however. In patients with moderate disease activity a reduction in the number of clinically active 
Table 3 Mean changes (95\% CI) and mean differences (95\% CI) in change scores between groups in variables of joint mobility, muscle strength, and functional ability in 64 patients randomly assigned to an intensive or conservative exercise programme during a stay in hospital

\begin{tabular}{|c|c|c|c|c|c|}
\hline & \multicolumn{2}{|c|}{ Intensive exercise } & \multicolumn{2}{|c|}{ Conservative exercise } & \multirow[b]{2}{*}{ Mean difference $(95 \% \mathrm{CI})$} \\
\hline & $n$ & $\Delta^{\star} 95 \% C I^{\star}$ & $n$ & $\triangle 95 \% C I$ & \\
\hline \multicolumn{6}{|c|}{ foint mobility, EPM-ROM ${ }^{\star}$ scale $(0=$ full flexibility $)$} \\
\hline Baseline $\left(\mathrm{SD}^{\star}\right)$ & 34 & $11.2(2.8)$ & 30 & $10.4(3.3)$ & \\
\hline$\Delta$ week 3 & 31 & $-0.7(-1.4$ to 0.1$)$ & 28 & $-0.7(-1.5$ to 0.1$)$ & $0.0(-1.1$ to 1.1$)$ \\
\hline$\Delta$ week 6 & 28 & $-0.5(-1.4$ to 0.5$)$ & 27 & $-0.5(-1.3$ to 0.3$)$ & $0.1(-1.2$ to 1.3$)$ \\
\hline$\Delta$ week 12 & 28 & $-1.6(-2.6$ to -0.5$)$ & 24 & $-0.6(-1.4$ to 0.3$)$ & $-1.0(-2.3$ to 0.3$)$ \\
\hline$\Delta$ week 24 & 28 & $-1.5(-2.5$ to -0.5$)$ & 20 & $-0.9(-2.1$ to 0.8$)$ & $-0.7(-2.2$ to 0.8$)$ \\
\hline \multicolumn{6}{|c|}{ Isokinetic extension $60^{\circ} / \mathrm{s}(0-13)$} \\
\hline Baseline (SD) & 34 & $5.7(2.5)$ & 30 & $6.0(3.6)$ & \\
\hline$\Delta$ week 3 & 33 & $1.2(0.2$ to 2.1$)$ & 29 & $0.2(-0.9$ to 1.3$)$ & $0.9(-0.4$ to 2.3$)$ \\
\hline$\Delta$ week 6 & 30 & $1.0(-0.5$ to 2.4$)$ & 25 & $0.5(-0.6$ to 1.6$)$ & $0.5(-1.3$ to 2.3$)$ \\
\hline$\Delta$ week 12 & 29 & $2.4(1.6$ to 3.2$)$ & 22 & $0.6(-0.8$ to 1.9$)$ & $1.8(0.3$ to 3.3$) \dagger$ \\
\hline$\Delta$ week 24 & 28 & $2.1(0.8$ to 3.3$)$ & 17 & $0.0(-1.6$ to 1.6$)$ & $2.3(0.0$ to 4.6$) \dagger$ \\
\hline \multicolumn{6}{|c|}{ Isometric extension ( $0-13)$} \\
\hline Baseline (SD) & 34 & $4.1(1.8)$ & 30 & $4.8(2.5)$ & \\
\hline$\Delta$ week 3 & 33 & $1.5(0.8$ to 2.1$)$ & 29 & $0.0(-0.8$ to 0.8$)$ & $1.5(0.5$ to 2.5$) \dagger$ \\
\hline$\Delta$ week 6 & 30 & $1.0(0.2$ to 2.2$)$ & 26 & $0.3(-0.4$ to 1.0$)$ & $0.7(-0.6$ to 2.1$)$ \\
\hline$\Delta$ week 12 & 29 & $2.7(1.8$ to 3.5$)$ & 24 & $0.5(-0.4$ to 1.4$)$ & $2.1(0.9$ to 3.3$) \dagger$ \\
\hline$\Delta$ week 24 & 28 & $2.1(1.1$ to 3.1$)$ & 21 & $0.2(-1.2$ to 1.6$)$ & $1.9(0.3$ to 3.5$) \dagger$ \\
\hline \multicolumn{6}{|c|}{50 foot walk test (s) } \\
\hline Baseline (SD) & 34 & $20.2(9.8)$ & 30 & $18.5(11.1)$ & \\
\hline$\Delta$ week 3 & 31 & $-3.9(-5.9$ to -1.9$)$ & 27 & $-2.8(-6.6$ to 1.0$)$ & $-1.1(-5.2$ to 3.0$)$ \\
\hline$\Delta$ week 6 & 29 & $-5.3(-8.1$ to -2.5$)$ & 26 & $-3.5(-8.2$ to 1.2$)$ & $-1.8(-7.0$ to 3.5$)$ \\
\hline$\Delta$ week 12 & 28 & $-6.6(-9.6$ to -3.6$)$ & 23 & $-5.2(-9.5$ to -1.0$)$ & $-1.4(-6.3$ to 3.4$)$ \\
\hline$\Delta$ week 24 & 27 & $-7.6(-11.3$ to -4.0$)$ & 18 & $-6.4(-12.0$ to -0.7$)$ & $-1.2(-7.5$ to 5.0$)$ \\
\hline \multicolumn{6}{|l|}{$H A Q$} \\
\hline Baseline (SD) & 34 & $1.8(0.8)$ & 30 & $1.7(0.6)$ & \\
\hline$\Delta$ week 3 & 28 & $-0.2(-0.4$ to 0.0$)$ & 29 & $-0.1(-0.3$ to 0.0$)$ & $-0.1(-0.4$ to 0.2$)$ \\
\hline$\Delta$ week 6 & 25 & $-0.4(-0.7$ to -0.4$)$ & 24 & $-0.2(-0.3$ to 0.0$)$ & $-0.2(-0.6$ to 0.2$)$ \\
\hline$\Delta$ week 12 & 25 & $-0.4(-0.8$ to -0.4$)$ & 20 & $-0.2(-0.5$ to 0.0$)$ & $-0.2(-0.6$ to 0.2$)$ \\
\hline$\Delta$ week 24 & 25 & $-0.5(-0.9$ to -0.2$)$ & 17 & $-0.3(-0.7$ to 0.0$)$ & $-0.2(-0.7$ to 0.3$)$ \\
\hline
\end{tabular}

${ }^{\star} \Delta=$ mean change; $\mathrm{CI}=$ confidence interval; $\mathrm{SD}=$ standard deviation; EPM-ROM scale = Escola Paulista de Medicina Range of Motion Scale; HAQ = Health Assessment Questionnaire

†Significant difference between groups.

joints after vigorous exercise has been observed. ${ }^{17}{ }^{18}$ It might be speculated that the improved muscle function in stabilising joints has a positive effect on joint inflammation. Furthermore, there is some evidence that intermittent cycles of intra-articular pressure rise during dynamic exercise might increase the synovial blood flow, suggesting a beneficial effect of dynamic exercises in joint inflammation. ${ }^{28}$ Further research is needed on the interaction between exercise and joint inflammation.

Our study confirms previous findings that training of muscle strength on an isokinetic device does not enhance joint inflammation. ${ }^{29}$ The isokinetic dynamometer enables adjustments in the range of motion in the case of painful and inflamed joints. In many exercise sessions adjustments to the exercise load were necessary because of pain or fatigue. This study shows that isokinetic training during active disease, if closely supervised, and adjusted when necessary, is well tolerated and more effective than a traditional exercise regimen of isometric exercises.

In the first three weeks patients in the conservative exercise programme showed a steeper decline in pain than the patients in the intensive exercise programme. Both patients groups had to keep to fixed hours for rest, but owing to the nature of the study, patients assigned to the intensive exercise programme, which was supplemental to the conservative exercise programme, were more engaged in exercise activities than the patients in the con- servative exercise programme. The lower rate in improvement in subjective outcome measures, such as pain and tiredness in the patients in the intensive exercise group, might be attributed to the extra time spent on exercises. In our opinion rest and exercise are complementary elements of the management of active disease and the best balance should be found between the beneficial effects of rest and exercise for each patient. Therefore, only those exercise forms should be applied which are known to be most effective in maintaining and improving function. Furthermore, instruments need to be found to monitor pain during exercise treatment to make an individually tailored exercise programme possible. A VAS for pain might be an appropriate instrument to harmonise the exercise load with the patient's need for rest.

In the Netherlands until the 1980s it was common to admit patients with active RA to hospital, sometimes for a long period of time. Over the past decades the frequency and duration of stay in hospital for active RA have decreased rapidly, following the general tendency to keep people out of hospital and limit healthcare costs. ${ }^{30}$ Nowadays, health policy focuses on a substitution of inpatient multidisciplinary care with outpatient care. The primary aim of the study was to examine the safety of intensive exercise in active RA. As the participating patients were admitted to hospital we were able to monitor accurately the amount of exercise and the amount and rest. However, in our view the results of our study are also generalisable to outpatients with active RA. 
The main conclusion drawn from this study is that there is no evidence that patients with active disease should be restrained from vigorous exercising.

The results of our study are encouraging, but several issues need to be considered in the future. Firstly, a relevant improvement in functional ability assessed by HAQ was found, but a statistically significant improvement in HAQ score was not established. This is probably owing to the small sample sizes and the relative low sensitivity to change of the HAQ score. Secondly, we only examined the safety of intensive exercise for pain, disease activity, and joint status. The effect of intensive exercise on erosions and cartilage damage remains unclear. Further research with larger sample sizes needs to be done on the benefit and disadvantages of a continued regimen of intensive exercise in RA. On the basis of the results of this study we suggest that patients with RA should be encouraged to continue their exercise during active disease.

The study was financially supported by "ZorgOnderzoek Nederland", the Netherlands.

1 Swezey RL. Rehabilitation medicine and arthritis. In: McCarty DJ, Koopman WJ, medicine and arthritis. In: McCarty DJ, Koopman
conditions. 1993: 887-917.

2 Scott DL. Rest or exercise in inflammmory arthritis? Br J Hosp Med 1992;48:445-7.

3 Semble EL. Rheumatoid arthritis: new approaches for its evaluation and management. Arch Phys Med Rehabi 1995;76:190-201.

4 Partridge REH, Duthie JJR. Controlled trial of the effect of complete immobilization of the joints in rheuamtoid arthritis. Ann Rheum Dis 1963;22:91-9.

5 Alexander GJM, Hortas C, Bacon PA. Bed rest, activity and the inflammation of rheumatoid arthritis. Br J Rheumatol 1983;22:134-40.

6 Mills JA, Pinals RS, Ropes MW, Short CL, Sutcliffe J. Value of bed rest in patients with rheumatoid arthritis. N Engl J Med 1971;284:453-8.

7 Suzuki Y, Murakami T, Haruna Y, Kawakubo K, Goto S, Makita Y, et al. Effects of 10 and 20 days bed rest on leg muscle mass and strength in young subjects. Acta Physiol Scand Suppl 1994;616:5-18.

8 White MJ, Davies CT, Brooksby P. The effects of short-term White MJ, Davies CT, Brooksby P. The effects of short-term
voluntary immobilization on the contractile properties of the human triceps surae. Quarterly Journal of Experimental Physiology 1984;69:685-91.

9 Veldhuizen JW, Verstappen FT, Vroemen JP, Kuipers H, Greep JM. Functional and morphological adaptation following four weeks of knee immobilization. Int J Sports Med 1993;14:283-7.

10 Vaughan VG. Effects of upper limb immobilization on isometric muscle strength, movement time, and triphasic electromyographic characteristics. Phys Ther 1989;69: $119-29$.

11 Duchateau J, Hainaut K. Effects of immobilization on contractile properties, recruitment and firing rates of human motor units. J Physiol (Lond) 1990;422:55-65.
12 Haggmark T, Eriksson E, Jansson E. Muscle fiber type changes in human skeletal muscle after injuries and immochanges in human skeletal muscle after
bilization. Orthopedics 1986;9:181-5.

13 Rutherford OM, Jones DA, Round JM. Long-lasting unilateral muscle wasting and weakness following injury and immobilisation. Scand J Rehabil Med 1990;22:33-7.

14 Young A, Hughes I, Round JM, Edwards RHT. The effect of knee injury on the number of muscle fibres in the human quadriceps femoris. Clin Sci 1982;62:227-34.

15 Greenleaf JE, Bernauer EM, Ertl AC, Trowbridge TS, Wade $\mathrm{CE}$. Work capacity during 30 days of bed rest with isotonic and isokinetic exercise training. J Appl Physiol 1989;67: 1820-6.

16 Ekdahl C, Andersson SI, Moritz U, Svensson B. Dynamic versus static training in patients with rheumatoid arthritis. Scand J Rheumatol 1990;19:17-26.

17 Minor MA, Hewett JE, Webel RR, Anderson SK, Kay DR. Efficacy of physical conditioning exercise in patients with rheumatoid arthritis and osteoarthritis. Arthritis Rheum 1989;32:1396-405.

18 Van den Ende CHM, Hazes JMW, le Cessie S, Mulder WJ, Belfo DG, Breedveld FC, et al. Comparison of high and low intensity training in well controlled rheumatoid arthritis. Results of a randomised clinical trial. Ann Rheum Dis 1996;55:798-805.

19 Arnett FC, Edworthy SM, Bloch DA, McShane DJ, Fries JF, Cooper NS, et al. The American Rheumatism Association 1987 revised criteria for the classification of rheumatoid arthritis. Arthritis Rheum 1988;31:315-23.

20 Fuchs HA, Pincus T. Reduced joint counts in controlled clinical trials in rheumatoid arthritis. Arthritis Rheum 1994;37:470-5.

21 Prevoo MLL, van't Hof MA, Kuper HH, van Leeuwen MA, van de Putte LBA, van Riel PLCM. Modified disease activity scores that include twenty-eight joint counts. Development and validation in a prospective longitudinal study of patients with rheumatoid arthritis. Arthritis Rheum 1995; 38:44-8.

22 Felson DT, Anderson JJ, Boers M,Bombarier C, Furst D, Goldsmith C, et al. American College of Rheumatology preliminary definition of improvement in rheumatoid arthritis. Arthritis Rheum 1995;38:727-35.

23 Ferraz MB, Oliveira LM, Araujo PMP, Atra E, Walter SD. The EPM-ROM Scale: an evaluative instrument to be used in rheumatoid arthritis trials. Clin Exp Rheumatol 1990;8: 491-4.

24 Vliet Vlieland TPM, Van den Ende CHM, Breedveld FC, Hazes JMW. Evaluation of joint mobility in rheumatoid arthrits trials: the value of the EPM-range of motion scale. J Rheumatol 1993;20:2010-14

25 Fries JF, Spitz PW, Kraines RG, Holman HR. Measurement of patient outcome in arthritis. Arthritis Rheum 1980;23: $137-45$.

26 Siegert CEH, Vleming LJ, Vandenbroucke JP, Cats A. Measurement of disability in Dutch rheumatoid arthritis patients. Clin Rheumatol 1984;3:305-9.

27 Van den Ende CHM, Vliet Vlieland TPM, Munneke M, Hazes JMW. Dynamic exercise in rheumatoid arthritis: a systematic review. Br J Rheumatol 1998;37:677-87.

28 James MJ, Cleland LG, Gaffney RD, Proudman SM, Chatterton BE. Effect of exercise on 99mTc-DTPA clearance from knees with effusions. J Rheumatol 1994;21:501-4.

29 Lyngberg KK, Ramsing BU, Nawrocki A, Harreby M, Danneskiold-Samsøe B. Safe and effective isokinetic extension training in rheumatoid arthritis. Arthritis Rheum 1994;37:623-34.

30 Vliet Vlieland TPM, Zwinderman AH, Vandenbroucke JP, Breedveld FC, Hazes JMW. A randomised clinical trial of inpatient multidisciplinary treatment versus routine outpatient care in active rheumatoid arthritis. Br J Rheumatol $1996 ; 35: 475-82$ 